\title{
Novel therapies for treating atrial fibrillation
}

\author{
Raj Parikh, Philip J. Kadowitz \\ Department of Pharmacology, Tulane University School of Medicine, New Orleans, USA \\ Email: rparikh1@tulane.edu, pkadowi@tulane.edu
}

Received 24 May 2012; revised 23 June 2012; accepted 12 July 2012

\begin{abstract}
Atrial fibrillation is the most common cardiac arrhythmia and is a major risk factor for stroke, heart failure, and death. Current treatments focus on anticoagulation as well as rate-control and rhythm-control strategies. Frequent INR checks associated with warfarin along with several adverse side effects of antiarrhythmics have propelled investigations into novel treatments for atrial fibrillation. Research is focused not only on pioneering new pharmacological anticoagulation and anti-arrhythmic agents but also on improving surgical techniques in hopes of treating the arrhythmia. Here, we first briefly discuss the current treatment options, both pharmacological and non-pharmacological, for atrial fibrillation. We then present a focused review of recent animal and human investigations that examine the use of novel anticoagulation agents, mechanisms of new anti-arrhythmics, analyze potential triggers of atrial fibrillation, and highlight the role of genetics in atrial fibrillation.
\end{abstract}

Keywords: Atrial Fibrillation; Atrial Flutter; Arrhythmia; Anticoagulation; Stroke

\section{INTRODUCTION}

Atrial fibrillation (AF) is the most common cardiac arrhythmia and a major risk factor for stroke, heart failure, and death. It affects nearly 3 million Americans, a number that is expected to rise to 6 - 12 million by 2050 [1]. The prevalence of AF increases with age: It is $0.1 \%$ in people younger than $55,3.8 \%$ in people older than 60 , and $10 \%$ in those who are older than 80 . The lifetime risk of developing AF after the age of 40 years is $26 \%$ for men, and $23 \%$ for women [2]. The disease is associated with an approximate two-fold increase in mortality, along with a three-fold increase in the risk of heart failure and a five-fold increase in the risk of stroke [3,4]. Additionally, over one-third of AF patients are hospitalized annually, leading to estimated hospital costs of nearly \$26 billion per year [5]. Risk factors for AF include advanced age, male sex, prior cardiovascular disease, and other risk factors that also lead to cardiovascular disease [6,7].

AF consists of a rapid and irregular activation of the atria of the heart, resulting in a loss of normal sinus rhythm. Cardiovascular risk factors have strong associations with AF but the relationship between the two is still under investigation. Atrial ischemia, atrial inflammation, catecholamine excess, metabolic stress, and hemodynamic instability are all potential causes of AF. While the pathophysiology of AF is incompletely understood, the mechanism of AF involves an initiating event and a susceptible atrial substrate. Recent literature illuminates the role of this substrate, which can result in reentry, and the role of other electrophysiologic triggers and modulating factors [8]. Susceptible atrial substrate can be the result of poor autonomic tone, inflammation, atrial fibrosis, and structural remodeling and its existence results in a focal origin that is the source of AF [9].

AF is classified into three specific types of patterns: paroxysmal, persistent, and permanent. The American College of Cardiology defines paroxysmal AF as episodes of AF that terminate spontaneously within 7 days. Paroxysmal AF can present with many premature trial beats seen on holter monitoring in patients and it can also progress to permanent AF. If episodes last more than 7 days, they are called persistent AF. Persistent AF can be due to many cardiac diseases, and since it causes an uncontrolled, rapid ventricular rate, it can result in dilated cardiomyopathy and electrical remodeling of the heart. Permanent AF is defined as AF that has persisted for longer than 1 year [10].

The clinical presentation of AF varies greatly and the spectrum of symptoms ranges from asymptomatic AF with an irregularly irregular rhythm to cardiogenic shock or stroke. The generalized symptoms of AF may include palpitations, dyspnea, fatigue, syncope, and angina. On physical exam, auscultation of the heart will produce an irregularly irregular beat and a subsequent 12-lead electrocardiogram (ECG) will display irregularly irregular narrow complex tachycardia [4].

\section{CURRENT THERAPY- PHARMACOLOGICAL}

\subsection{Anticoagulation}

The CHADS2 score aids the physician in determining the 
specific anticoagulation therapy regimen for specific patients with AF because it helps predict the patient's stroke risk. Patients with AF contribute to almost $24 \%$ of all causes of ischemic stroke and long-term anticoagulation in these patients serves to reduce the risk of thromboembolism. The score is determined by the patient's history of congestive heart failure, hypertension, diabetes, age (greater than 75), and prior history of ischemic stroke or transient ischemic attack. Each characteristic is given 1 point if it is present in the patient's history, while a prior history of stroke is given 2 points [11]. A patient with a CHADS2 score of 0 has a $0.5 \%$ to $1.7 \%$ chance of stroke and therefore, no antithrombotic therapy, such as warfarin, is recommended. Studies have shown that low risk patients also do not benefit from aspirin. Those with a CHADS2 score of 1 are at intermediate risk and should be treated with oral anticoagulant therapy or aspirin. Social factors including patient preference can help determine whether a patient will be placed on antithrombotic therapy or aspirin, even though aspirin is proven to be less effective [12]. Patients at intermediate risk, who prefer not to be on antithrombotic therapy, could potentially be on dual antiplatelet therapy even though the efficacy of this regimen is not completely clear. The risks that come with dual antiplatelet therapy are similar to monotherapy regimens according to the ACTIVE W (Atrial fibrillation Clopidogrel Trial with Irbesartan for prevention of Vascular Events) trial [13]. With a CHADS2 score of 2 or higher, anticoagulant therapy is highly recommended [10]. Warfarin has been studied in multiple trials to be more effective than aspirin at reducing the clinical stroke risk in patients with AF [14]. Warfarin is effective in men and women of all age groups and it has shown to decrease mortality rates [15]. However, warfarin has a high risk of bleeding and therefore, levels must be closely monitored. An INR between 2.0 and 3.0 is generally considered therapeutic for patients with atrial fibrillation [16]. When the INR is below 2.0, there is an increase in severity of stroke and mortality rate [17].

\subsection{Rate-Control vs. Rhythm-Control}

In evaluating a pharmacologic treatment plan for patients with AF, both rate-controlled and rhythm-controlled strategies can be implemented to compliment the anticoagulation medications and provide symptomatic relief. A rhythm-controlled strategy utilizes anti-arrhythmic drug therapy in an effort to alter the underlying irregular rhythm. Meanwhile, a rate-controlled strategy uses medications that can serve to slow conduction through the atrioventricular node (AVN).

The AFFIRM (Atrial Fibrillation Follow-up Investigation of Rhythm Management) clinical trial compared the effects of rate-control and rhythm-control strategies in patients with recurrent AF [18]. All of the 4060 patients had to be at least 65 years old or have other risk factors for stroke or death. For the patients assigned to the ratecontrol therapy, the therapeutic goals were ventricular rate of $80 \mathrm{bpm}$ at rest and $110 \mathrm{bpm}$ during a six-minute walk test. At five years, $35 \%$ of patients were in sinus rhythm and over $80 \%$ of patients still in $\mathrm{AF}$ had adequate heart rate control. Radiofrequency ablation was used in cases where pharmacological therapy was ineffective, which included $5 \%$ of the patients in the rate-control arm of the study. Crossover to rhythm-control occurred in $8 \%$ of patients in one year and $15 \%$ of patients in five years due to failure to control symptoms caused by AF. Meanwhile, in the rhythm-control therapy patients, sinus rhythm was achieved in $82 \%$ of patients at one year and $63 \%$ of patients at five years. Nonpharmacological therapy was utilized in only $1 \%$ of patients. In the rhythm-control arm of the trial, crossover to rate-control occurred in $17 \%$ of patients at one year and $38 \%$ of patients at five years. This was primarily due to drug intolerance and an inability to maintain sinus rhythm [19]. After four years of analysis, the AFFIRM trial showed no difference between the two groups in the incidence of cardiac death, arrhythmic death, or deaths due to ischemic or hemorrhagic stroke [20]. There was also no difference in global functional status or quality of life seen between the two arms of the study. However, there was a significantly lower amount of patients who required hospitalization during follow-up in the rate-control group versus the rhythmcontrol group.

The RACE (Comparison of Rate Control and Rhythm Control in Patients with Recurrent Persistent Atrial Fibrillation) clinical trial enrolled 522 patients and, like the AFFIRM study, compared rate-control strategy with rhythm-control strategy [21]. The patients had recurrent persistent AF for less than one year and had a prior history of cardioversion. Data resulting from this study again did not show a difference in cardiovascular mortality between the two groups but it did show a higher incidence of heart failure, thromboembolism, pacemaker insertion, and adverse drug reactions in the rhythm-control arm of the trial.

Given the equal efficacy but potentially more adverse outcomes with rhythm control, the American College of Cardiology guidelines recommend rate-control strategy over rhythm-control. However, in patients with persistent symptoms while on rate-control therapy, rhythm-control strategy is an alternative option. Additionally, an initial rhythm-control strategy can be used in younger patients who do not have comorbid cardiovascular disease. Older patients with structural cardiac disease are less likely to convert and remain in sinus rhythm and also have more adverse effects from anti-arrhythmic drugs. Thus, longterm rate-control is the best strategy in these individuals [22]. 
Rate-control therapy includes the use of beta blockers, non-hydropyridine calcium channel blockers, or digoxin to slow AVN conduction. The RACEII (Comparison of Rate Control and Rhythm Control in Patients with Recurrent Persistent Atrial Fibrillation) trial looked at 614 physically active patients with permanent AF and compared a lenient rate-control strategy with a strict ratecontrol strategy [21]. Results showed that strict heart rate control with defined parameters is not necessary in patients who are both physically active and minimally symptomatic. In patients who are not able to achieve adequate rate control with a single agent, combination rate-control therapy is indicated. The AFFIRM trial demonstrated that combined beta-blocker and calcium-channel blocker therapy was more effective than the single agents (76\% versus $59 \%$ for beta-blocker alone and $38 \%$ for calcium channel blocker alone).

Rhythm-controlled therapy requires treating the cardiovascular risk factors and other underlying disorders that may be contributing to the AF. The primary goal of the rhythm-control strategy is to reduce symptoms by decreasing the frequency and duration of episodes [23]. Anti-arrhythmic drugs have shown to be effective in converting AF to sinus rhythm. However, these medications must be chosen carefully due to multiple adverse effects of the drugs. A systematic review that included 44 clinical trials examining various anti-arrhythmic drugs for treatment of AF, noted that class IA, class IC, and class III drugs decreased the recurrence rate of AF with odds ratios of $0.51,0.36$, and 0.37 , respectively [24]. Additionally, amiodarone, a class III agent, was found to be the most effective anti-arrhythmic agent while class IA drugs were associated with increased mortality in comparison to the other medications. The class IA anti-arrhythmics include quinidine, disopyramide, and proca- inamide and they act by modifying the sodium channel and inhibiting the outward potassium current resulting in QT prolongation. The class IC drugs include flecainide and propafenone, and both have been shown to have equal efficacy in prolonging the time to AF recurrence [25]. Unfortunately, the class IC drugs are not commonly used due to their cardiac complications including wors- ening heart failure, bradycardia, and drug-induced atrial and ventricular arrhythmias in 7 to $27 \%$ of cases [26]. Therefore, flecainide is only used in patients who have no evidence of structural heart disease and the class IC drugs, in general, are restricted in their use due to addi- tional findings from the CAST (Cardiac Arrhythmia Suppression Trial) trial [27]. Class III drugs include amio- darone, sotalol, dofetilide, and ibutilide. Amiodarone, especially in patients with coronary artery disease or heart failure, is first line because it has decreased pro- arrhythmic effects in comparison to the other anti-ar- rhythmic medications [28]. Additionally, amiodarone is more effective in maintaining sinus rhythm than the other agents. Dofetilide was investigated in the SAFIRE-D (Symptomatic Atrial Fibrillation Investigative Research on Dofetilide) study where 30\% of patients achieved cardioversion within 36 hours and 58\% remained in si- nus rhythm at one year [29]. This class III anti-arrhyth- mic has reverse use dependence and a narrow therapeutic range where doses must be adjusted based on renal func- tion [30]. Castro et al. showed that dofetilide only had 28\% efficacy in treating AF and was much more effect- tive in the treatment of atrial flutter (66\% efficacy) [31]. Similarly, ibutilide is more effective in terminating atrial flutter than it is AF and it also has a $2.4 \%$ incidence of torsades de pointes. Meanwhile, sotalol has been shown to be useful in preventing recurrent episodes though it is not very effective in converting $\mathrm{AF}$ to sinus rhythm [32].

\section{CURRENT THERAPY- NONPHARMACOLOGICAL}

\subsection{Surgical Procedures}

Nonpharmacological therapy for AF has been critical to the overall successful treatment of the disease due to limited anti-arrhythmic agents and often pro-arrhythmic side effects of these drugs. Common indications for implementing nonpharmacological therapy are paroxysmal AF with very frequent attacks and severe symptoms, chronic AF without adequate rate-control leaving the patient at risk of developing tachycardiomyopathy, or patients who cannot withstand the side effects of drug therapy. There are two primarily used nonpharmacological strategies for treatment of AF: catheter-based radiofrequency ablation (RFA) and surgical therapy. Catheter ablation has been compared to surgical therapy in treatment of AF and studies have shown that surgical ablation was more effective than catheter-based techniques in abolishing left atrial arrhythmias after 12 months of follow-up but the surgical ablation procedure came with an increased risk of complications, including postoperative pneumothorax, major bleeding, and an eventual need for permanent pacing [33].

Surgical strategies for treatment of AF focus on interrupting the atrial substrate, maintaining atrioventricular synchrony, and preserving atrial mechanical function in an attempt to improve diastolic filling [34]. In the 1990s, the Maze I procedure created a maze of functional myocardium within the atrium that would allow atrial depolarization to propagate forward and avoid re-entry. Since then, the procedure has undergone improvements. The Maze II procedure corrected the chronotropic incompetence that existed with Maze I by making small incisions around the sino-atrial (SA) node and at the atria-superior vena cava junction. Further modifications resulted in the 
Maze III procedure, which not only served to reduce the chronotropic incompetence but also improved atrial transport function and shortened procedure times [35,36]. A five-year study highlighted the efficacy of the Maze III procedure by showing that 74 of the 75 patients that underwent the surgery were cured of AF and also had restored atrioventricular synchrony and preserved atrial transport function [37]. Another study showed that 89.3\% of patients who underwent the Maze procedure were cured from AF at a 10-year follow-up [38]. However, atrial dysfunction due to damaged atrial myocardium can result from the Maze procedure [39]. Additionally, partial denervations of the sympathetic and parasympathetic systems of the heart can lead to sinus node dysfunction, resulting in sinus bradycardia, sinus pauses, SA exit block, atrial tachyarrhythmias, or inappropriate heart rate responses to exercise or stress [40].

Another surgical technique, the radial approach, involves incisions that radiate from the sinus node toward the atrioventricular annular margins, thereby mimicking the activation-contraction sequence of the heart and the atrial coronary arteries [41]. In comparison to the Maze procedure, this approach reduces the degree of left atrial dysfunction and also maximizes the atrial contribution to left ventricular filling [42]. Therefore, the radial approach not only is easier than the Maze procedure, but also proves to be just as effective in restoring sinus rhythm and potentially more effective at enhancing left atrial transport function [43].

The corridor procedure involves electrically isolating the sinus node, a strip of atrial tissue, and the AVN from the rest of the atria [44]. This causes the free wall tissue of both atria to fibrillate while both ventricles are still being activated by the SA node. However, because the corridor technique fails to preserve atrial transport or improve atrioventricular synchrony, it is not as effective and not as popular as the Maze procedure.

In paroxysmal AF, there are ectopic foci that are localized 2 to $4 \mathrm{~cm}$ inside the pulmonary veins, with the left superior vein being the most common [45]. Therefore, pulmonary vein isolation techniques have created a different avenue to treat AF. Not only have studies shown that this surgical strategy can be effective in restoring sinus rhythm in AF but one report also showed that pulmonary vein isolation techniques are more effecttive in maintaining sinus rhythm than the Maze operation [46]. Thoracoscopic pulmonary vein isolation and ablation has proven to be a minimally invasive procedure that can treat AF patients who have failed drug therapy or catheter-based pulmonary vein RFA [47]. This technique involves electrical isolation of the pulmonary veins and has shown to be more effective in making patients arrhythmia-free in comparison to pulmonary vein RFA as reported by the FAST (Atrial Fibrillation Catheter Abla- tion versus Surgical Ablation Treatment) trial [33]. Despite this improved efficacy, this minimally invasive procedure had a much higher incidence of periprocedural complications, including pneumothorax, major bleeding, and the need for a pacemaker.

\subsection{Ablation Procedures}

Catheter-based RFA attempts to eliminate the triggers of AF and modify the atrial substrate, similar to the goals of surgical strategies in treating AF. These triggers have been studied throughout the years and this research has helped drive the strategy and efficacy involved in ablation techniques. While focused ectopic sites are present in paroxysmal $\mathrm{AF}$, in persistent $\mathrm{AF}$, multiple ectopic sites are distributed within the atria and therefore, RFA procedures that target the pulmonary veins are not as effective in cases of longstanding AF [48].

Pulmonary vein RFA involves two principal techniques: segmental ostial pulmonary vein ablation and circumferential ablation of left atrial tissue. In segmental ostial isolation, a circular catheter is placed at the orifice of the pulmonary vein, electrodes are used to detect connections between the vein and atrium and then, these sites undergo ablation [49]. Circumferential ablation of the left atrial tissue involves confluent ablation lesions that surround the ostia of all the pulmonary veins along with additional ablation lesions. In evaluating the two techniques of pulmonary vein RFA, studies have shown conflicting results. One investigation analyzed 80 patients with symptomatic paroxysmal AF and showed a higher success rate with circumferential left atrial ablation at six-month follow-up in comparison to segmental ostial pulmonary vein isolation [50]. However, another study found contradictory results when 100 patients were randomly assigned to either technique and followed up in a more extensive manner, including holter monitoring. This study demonstrated a higher rate of AF recurrence in the group that underwent the circumferential ablation [51]. While it remains controversial which technique is more effective, it is clearer that more obvious complications result from circumferential ablation, including higher rates of left atrial flutter, asymptomatic pericardial effusions, atrioesophageal fistula, and pyloric spasms with gastric hypomotility [50-53]. Regardless of technique, the end goal of pulmonary vein RFA is to achieve isolation and to avoid AF recurrence. Investigations have shown that RFA therapy is not entirely successful, as early AF recurrence is common (35\% of all recurrences) in the first two weeks following the procedure [54]. This transient AF recurrence is possibly caused by sterile pericarditis following RFA, recovered pulmonary vein conduction, or pro-arrhythmic effects of the ablation procedure itself [55]. Late AF recurrence is commonly 
believed to be a result of incomplete pulmonary vein isolation and less commonly due to multiple triggering foci outside of the pulmonary veins $[56,57]$. While the pulmonary veins are the most common source of AF triggers, other sites do exist, with another common location being the left atrial appendage [58].

While RFA of the pulmonary vein is the most common therapeutic option for nonpharmacological treatment of AF, cryothermal energy has recently been adopted as an alternative source for the ablation procedure. The cryoballoon technique has been successful in pulmonary vein isolation procedures in animal models as well as humans $[59,60]$. Linhart et al. performed a casecontrol study comparing cryoballoon ablation and RFA of the pulmonary veins and results showed that of the 20 patients who had the cryothermal energy ablation, 55\% were free of $\mathrm{AF}$ at 3 and 6 month follow-up while only $45 \%$ were symptom free in the RFA arm of the study [61]. While the design of the investigation as a casecontrol comparison of 2 patient groups comes with its own general limitations, the results are still important in dictating a potential shift in technique for future ablation procedures. RFA has several potential complications including pulmonary vein stenosis, pericardial effusion, atrioesophageal fistula, thromboembolism, and left atrial flutter [52,62-63]. With a shift to cryothermal energy as the source of the ablation procedure, many of these procedural complications can be avoided. However, cryoballoon catheters do come with their own set of complications as 3 patients in this study suffered from phrenic nerve palsies though they eventually resolved spontaneously.

The most common nonpharmacological therapy of ratecontrol used to treat AF is catheter-based RFA of the AVN. The NASPE Prospective Catheter Ablation Registry in 1998 showed that AVN ablation was successful in 97.4\% of 646 patients and the prospective APT (Ablate and Pace trial) trial showed $99.4 \%$ effectiveness of the procedure $[64,65]$. Additionally, a meta-analysis that included 21 individual studies and a total of 1181 patients noted significant improvement in quality of life, ventricular function, and exercise duration [66]. However, AVN ablation therapy has yet to statistically show improvements in overall survival in patients with AF [67]. While AVN ablation procedures have been at the forefront of nonpharmacological therapy of AF, the method has its share of complications and almost $3 \%$ of patients suffered ventricular fibrillation (VF) and sudden cardiac death in a review of 334 patients [68]. Potential causes of VF include underlying heart disease, activation of the sympathetic nervous system, prolongation in action potential duration, or repolarization abnormalities induced by bradycardia. However, post-ablation pacing has shown to decreased the incidence of VF [69]. Therefore, following the AVN ablation procedure, patients rely on a permanent pacemaker and the type of pacemaker depends on the patients' overall clinical profile. A singlechamber ventricular pacemaker is often used in patients with chronic AF. Paroxysmal AF requires a dual chamber pacemaker because they are better at maintaining AV synchrony during periods of sinus rhythm [70]. Cardiac resynchronization therapy (CRT) and implantable cardioverter-defibrillators (ICDs) can also be used to help improve interventricular desynchrony that follows AVN ablation and right ventricular pacing. Furthermore, AVN conduction can be modified, rather than completely ablated, and still be potentially successful in controlling the ventricular rate in AF patients. RFA can be applied to a section of the AVN and help reduce the number of impulses that are sent to the infranodal conduction system and on to the ventricles [71,72]. This technique may be beneficial in that it can eliminate the need for a pacemaker; however, it has been shown to be less effective than AVN ablation [73].

\section{NOVEL THERAPY- PHARMACOLOGICAL}

\subsection{Anticoagulation}

While warfarin has proven to be very effective, the dependence on INR checks and the inconvenience they cause to the patients are often a reason why those suffering from AF look for alternative solutions to decrease their thromboembolic risk. Warfarin also has a significant risk of major bleeding. Similarly, aspirin and an aspirin-clopidogrel combination also have a risk of major bleeding. The BAFTA (Birmingham Atrial Fibrillation Treatment of the Aged study) study in 2007 and the ACTIVE-W (Atrial fibrillation Clopidogrel Trial with Irbesartan for prevention of Vascular Events) study in 2006 highlighted these side effects [74,75]. Novel anticoagulant drugs potentially allow for application at fixed doses and eliminate the need for constant monitoring. Additionally, with decreased risk of bleeding, these agents could revolutionize therapy for patients with AF. Direct thrombin inhibitors, such as ximelagatran and dabigatran, and factor Xa inhibitors are some of the classes of drugs being studied for anticoagulation therapies.

\subsubsection{Direct Thrombin Inhibitors}

Ximelagatran was initially evaluated for thromboembolic prophylaxis following orthopedic procedures and it showed superior efficacy over warfarin [76]. Further evaluation was obtained from the double-blinded SPORTIF V (The Stroke Prevention Using an Oral Thrombin Inhibitor in Atrial Fibrillation) trial, which enlisted 3922 AF patients for 20 months [77]. Results showed a 1.6\% risk for stroke in patients treated with ximelagatran com- 
pared to $1.2 \%-2.6 \%$ for warfarin. Additionally, bleeding occurred less frequently in the ximelagatran arm of the study. Despite these benefits, ximelagatran was taken off the market in 2006 because of an adverse effect on liver function, with complications occurring in roughly $6 \%$ of patients.

Dabigatran, another direct thrombin inhibitor, was also originally studied in the post-operative orthopedic surgery setting in the RE-NOVATE (Dabigatran Etexilate Compared With Enoxaparin in Prevention of VTE Following Total Hip Arthroplasty) and RE-MODEL (DabigatranEtexilate 150 or $220 \mathrm{mg}$ o.d. vs. Enoxaparin $40 \mathrm{mg}$ o.d. for Prevention of Thrombosis After Knee Surgery) trials $[78,79]$. Both trials failed to show any superiority of dabigatran over enoxaparin. Despite its failure in the orthopedic realm, dabigatran was investigated for stroke prevention in AF patients in the PETRO (Prevention of Embolic and Thrombotic events) phase II trial [80]. The 502-patient PETRO trial showed a clear reduction in thromboembolic events with dabigatran doses of either 150 or $300 \mathrm{mg}$ twice daily. The findings from the PETRO trial fueled a larger, phase III trial called RE-LY (Randomized Evaluation of Long-term anticoagulation therapy) [81]. The RE-LY trial compared dabigatran to warfarin in 18,113 patients with follow-up at 2 years and showed that there was a similar incidence of ischemic stroke in patients taking dabigatran $110 \mathrm{mg}(1.5 \%)$ and warfarin (1.7\%). However, in patients who were given dabigatran $150 \mathrm{mg}$, the incidence of stroke was less than the warfarin group at $1.1 \%$. Hemorrhagic stroke also occurred less on both low-dose $(0.12 \%)$ and high-dose dabigatran $(0.10 \%)$ when compared to warfarin $(0.38 \%)$. Additionally, the bleeding rate was lower in the low-dose dabigatran in comparison to warfarin and the all-cause mortality rate was decreased with $150 \mathrm{mg}$ dabigatran when compared to warfarin. The RE-LY study concluded that low-dose dabigatran is at least equally effective as warfarin while high-dose dabigatran is superior in efficacy. Unlike ximelagatran, no significant rise in liver enzymes were noted in the dabigatran trials but a potential interaction with P-glycoprotein-inhibitors such as amiodarone, verapamil, or quinidine could lead to increased plasma concentrations of the drug, and thus, a potential for increased bleeding. Nevertheless, dabigatran could overtake warfarin as the primary anticoagulation therapy in patients with AF. It offers clear benefits in stroke prevention, mortality, and decreased risk of bleeding as delineated by the RE-LY trial. Moreover, dabigatran does not require the frequent INR monitoring of warfarin. However, there is no easily available agent to reverse the effects of dabigatran and it's dose must be altered in patients with renal dysfunction. While further analysis has yet to be done, there is a high likelihood that total cost effectiveness of dabigatran will be superior to warfarin if it means the costs of stroke could be reduced.

\subsubsection{Factor Xa Inhibitors}

Factor Xa inhibitors work by blocking the conversion of prothrombin to thrombin. They include rivaroxaban and apixaban. Rivaroxaban has been investigated in phase III orthopedic trials, such as the RECORD1 (Rivaroxaban [10 mg] Given Once Daily in Patients Undergoing Total Hip Replacement Compared to Enoxaparin) study [82]. In the RECORD1 trial, 4541 patients were followed over 5 weeks after hip replacement operations and rivaroxaban was shown to decrease the risk of thrombosis or embolism more than $70 \%$ when compared to enoxaparin. The phase III trial, ROCKET-AF (Randomized, Double-Blind Study Comparing Once Daily Oral Rivaroxaban With Adjusted-Dose Oral Warfarin for the Prevention of Stroke in Subjects with NonValvular Atrial Fibrillation), enlisted 14,000 patients and compared the efficacy of rivaroxaban $20 \mathrm{mg}$ with warfarin [83]. Results from the double-blinded ROCKET-AF trial proved that rivaroxaban was superior to warfarin when analyzing the risk of stroke and embolism in patients who were treated for 40 months. Also, the rate of bleeding was slightly lower in the rivaroxaban-treated patients [84].

Like its predecessors, apixaban was also first evaluated in the orthopedic literature. The ADVANCE-1 (Study of an Investigational Drug for the Prevention of Thrombosis-Related Events Following Knee Replacement Surgery) trial was a phase III investigation that failed to show the superiority of apixaban over enoxaparin, though it did demonstrate a lower risk of bleeding [85]. However, the ADVANCE-2 trial disputed the first trial and showed improved efficacy of anticoagulation for apixaban. In the ARISTOTLE (Apixaban for the Prevention of Stoke in Subjects with Atrial Fibrillation) trial, 18,206 patients were enlisted and apixaban was compared with warfarin [86]. The apixaban group was shown to have a significantly reduced primary composite endpoint of stroke and systemic embolism in comparison to the warfarin group. There was also a reduction in the rate of all-cause mortality in the apixaban group compared to the warfarin group. Additionally, apixaban has also been compared to aspirin in patients with AF who had contraindications to warfarin therapy. This study, the AVERROES trial (Study of Apixaban in Patients with Atrial Fibrillation), highlighted apixaban's superiority over aspirin in reducing thromboembolic events as a $56 \%$ reduction in stroke or embolism was seen in the patients treated with apixaban [87].

While these novel anticoagulation agents create new opportunities for the reduction of thromboembolic risk in patients with AF, they also have potential limitations. The notion that patients no longer need to be monitored closely with INR checks and drug therapeutic levels im- 
plies that patients will be less monitored regularly as a whole. Also, many of the direct thrombin and Factor Xa inhibitors require twice daily dosing, which has the potential to lower effectiveness of the drug if patients are noncompliant. At the same time, overdosing on these novel treatment options can be a problem since effective antidotes have yet to be investigated.

\subsection{Anti-Arrhythmics}

While current anti-arrhythmic medications have shown clinical success in treating AF, many of them are accompanied with significant adverse side effects. Thus, novel anti-arrhythmic agents with both conventional antiarrhythmic mechanisms and unconventional modes of action are being investigated.

\subsubsection{Class III Agents}

Some of the new class III anti-arrhythmics include azimilide, which works by blocking both the rapid-activating and slow-activating delayed rectifier currents of the potassium channels. In rapid AF, azimilide should be more effective than anti-arrhythmic agents that only inhibit the rapid-activating delayed rectifier current. The theory behind this is that the rapid-activating current has a decreased contribution to repolarization compared to the slow-activating current because of incomplete deactivation. Despite its theoretical advantages, azimilide has not shown great efficacy in clinical trials. In the ALIVE (Azimilide Post-Infarct Survival Evaluation) trial, 3717 patients who had suffered from a recent myocardial infarction and left ventricular dysfunction were evaluated [88]. Azimilide had no effect on all-cause mortality. When azimilide was studied in trials specific for AF, similar results were found. In the A-STAR (Supraventricular TachyArrhythmia Reduction) trial, azimilide did not provide any anti-arrhythmic benefit [89]. In ACOMET I and II (Cardioversion Maintenance Trial) trials, azimilide not only failed to show superior anti-arrhythmic effects but also displayed an increased risk for torsades de pointes [90,91].

Tedisamil, another class III compound, inhibits multiple potassium channels, including the rapidly activating delayed rectifier current and the transient outward current. It also has the ability to increase gap junctional conductance and conduction velocity and thus, prevent fast ventricular rates during AF recurrence. A dose-efficacy investigation enlisted 175 patients with minimal structural heart disease and recent-onset AF to evaluate the effects of tedisamil [92]. Results showed that $0.4 \mathrm{mg} / \mathrm{kg}$ tedisamil restored sinus rhythm in $41 \%$ of patients while $0.6 \mathrm{mg} / \mathrm{kg}$ tedisamil restored sinus rhythm in $51 \%$ of patients. However, the group given $0.6 \mathrm{mg} / \mathrm{kg}$ dose of tedisamil produced 2 patients who developed ventricular tachycardia. Additionally, because of the medication's inhibition of multiple potassium currents, side effects included diarrhea, hypokalemia, and a high potential for torsades de pointes. Therefore, tedisamil was not considered a long-term anti-arrhythmic option though it may have some use in acute pharmacological cardioversion in AF patients.

Nifekalant inhibits the rapidly-activating delayed rectifier current and is also a new class III compound. Morita et al. evaluated the drug in more detail and their investigations showed that nifekalant was ineffective in converting AF but was $75 \%$ successful in terminating atrial flutter [93]. The medication is currently being used in Japan as an agent for acute treatment of ventricular tachyarrhythmias refractory to other anti-arrhythmic medications.

Dronedarone has multiple electrophysiological effects and is quite similar to amiodarone except it lacks the iodine component and therefore has fewer side effects. Additionally, it is not known to significantly prolong the QT interval and thus, has a low potential to cause torsades de pointes [94]. The EURIDIS (European trial in atrial fibrillation or flutter patients receiving Dronedarone for the maintenance of Sinus rhythm) trial displayed dronedarone's ability to decrease the amount of AF recurrence [95]. The control group suffered from AF recurrence in 41 days while the dronedarone arm went 96 days before recurrence. The ADONIS (American-Australian Trial with Dronedarone in Atrial Fibrillation or Flutter Patients for the maintenance of Sinus rhythm) trial, an equivalent to the EURIDIS trial, showed that dronedarone prolonged the recurrence of AF to 158 days, while the placebo group lasted only 59 days [95]. In the ADONIS trial, all 630 subjects were post-cardioversion patients who were given a $400 \mathrm{mg}$ dose of dronedarone twice daily. Dronedarone was also shown to effectively control ventricular rates and this was further investigated by the ERATO (Efficacy and Safety of Dronedarone for the Control of Ventricular Rate) trial [96]. This study enlisted 630 patients who were suffering from permanent $\mathrm{AF}$ and had ventricular rates greater than $80 \mathrm{bpm}$ while already on rate-control therapy. Dronedarone lowered the ventricular rate by $12 \mathrm{bpm}$ when compared to placebo at 1-month follow-up. However, dronedarone also has the potential to cause adverse effects as was highlighted by the ANDROMEDA (Anti-arrhythmic trial with dronedarone in moderate to severe heart failure evaluating morbidity decrease) trial, which was prematurely terminated after 627 heart failure patients (EF less than 35\%) were enrolled [97]. In these patients, treatment with dronedarone resulted in worsening renal function and the subjects had to discontinue their ACEi (angiotensin-converting enzyme inhibitor) medications. Additionally, the PALLAS (Permanent Atrial Fibrillation Outcome Study 
Using Dronedarone on Top of Standard Therapy) trial, which involved 3236 patients was prematurely terminated due to safety reasons. Subjects had permanent $\mathrm{AF}$ and were given either dronedarone or placebo. Several complications were seen in the case subjects, including increased rates of heart failure, stroke, and death [97]. Nevertheless, a phase III randomized control study, the ATHENA (A placebo-controlled, double-blind, parallel arm trial to assess the efficacy of dronedarone 400 mg bid for the prevention of cardiovascular hospitalizetion or death from any cause in patients with atrial fibrillation/atrial flutter) trial, further explored the beneficial effects of dronedarone that were portrayed by the ADONIS, EURIDIS, and ERATO trials [98]. The ATHENA investigation wanted to take a closer look at all-cause mortality and hospitalizations in patients with paroxysmal or persistent AF. 4628 patients were enlisted and placed on 400 mg dronedarone and followed up in approximately 21 months. Results showed that dronedarone was able to prolong the time to first cardiac hospitalization by $25 \%$ compared to placebo and by $37 \%$ for hospitalizations specific for AF. While all-cause mortality was not statistically significant in comparing the placebo and dronedarone groups, there was a decrease in the number of deaths from cardiovascular cause in the dronedarone arm of the study.

While dronedarone is similar to amiodarone in its mode of action, there are other novel anti-arrhythmic agents that are amiodarone-derivatives, such as celivarone. Celivarone, like dronedarone, is noniodinated and has multiple channel-blocking properties. Preliminary studies in canine models showed that celivarone has the ability to terminate vagal-induced AF [99]. A phase II dose-ranging study, MAIA (Maintenance of sinus rhythm in patients with recent atrial fibrillation or flutter) trial took a closer look at the safety and efficacy of celivarone by enlisting 673 patients and randomizing them to 4 varying doses or placebo [100]. At 90 days, the lowest dose celivarone had an incidence of $52.1 \%$ of $\mathrm{AF}$ recurrence, compared to placebo incidence of $67.1 \%$. Another investigation, a double-blind placebo trial, CORYFREE (Controlled Dose-Ranging study of the efficacy and safety of SSR149744C 300 or $600 \mathrm{mg}$ for the conversion of atrial fibrillation/flutter), involved 150 patients with either AF or atrial flutter. They were randomly assigned to $300 \mathrm{mg}$ celivarone, $600 \mathrm{mg}$ celivarone, or placebo for a treatment period of 2 days and the study focused on the rate of conversion to sinus rhythm. Results of this trial have not yet been reported. Other amiodarone derivatives are also under development as attempts are being made to create modifications to amiodarone that could potentially allow for rapid hydrolization and thus, shorter half-life and more rapid action. One such derivative is ATI-2042, which was investigated by Arya et al. in a pilot study in patients with paroxysmal AF [101]. Results showed that the drug reduced the amount of time patients were in AF by $87 \%$ and thus, triggered development of a phase II study that plans to further analyze the efficacy and safety of the medication.

\subsubsection{Action Potential Modifying Agents}

Potential targets of novel anti-arrhythmic drugs include the slow-activating delayed rectifier potential channel. HMR1556, a selective slow-activating current inhibitor, has recently been studied in canine models of vagalinduced AF [102]. In this investigation, HMR1556 was able to prolong the atrial effective refractory period only in combination with beta-adrenergic stimulation. However, HMR1556 at higher concentrations loses its selectivity and also begins to inhibit multiple other currents, including the transient outward current. This aspect of the drug leads to its pro-arrhythmic predisposition and ultimately limits its potential as a suitable new treatment for AF.

\subsubsection{Atrial-Repolarization Delaying Agents}

Similar to the selective inhibition seen with HMR1556, other novel treatments that can maintain high selectivity for certain ion channels involved in atrial repolarization have the capability of being effective anti-arrhythmic agents in treating AF. The Kv1.5 channels carry the current that is a determinant of action potential shape in atrial myocytes. Inhibiting this channel, which is the role of atrial repolarization-delaying agents (ARDAs), opens up a new subtype of anti-arrhythmics that can potentially treat AF. ARDAs have shown to be more effective in remodeled atria in comparison to traditional class III potassium blocking agents like dofetilide and ibutilide [103]. However, at the same time, ARDAs can also block the Kv1.5 channels that are located in the ventricles and thus, could cause ventricular repolarization [104]. The most investigated ARDA is vernakalant, which was recently recommended for approval for cardioversion in AF. Vernakalant, in fact, works at multiple channels in an effort to slow conduction velocity within the atrium and prolong its recovery. A small, phase II study by Roy et al. in 2004 examined the effects of vernakalant on 30 patients with AF [105]. Varying doses of the drug were used and the study showed that the highest dose of vernakalant terminated AF in $61 \%$ of the patients within 80 minutes of exposure. The ACT (Atrial arrhythmia conversion trials) trials I, II, III, and IV analyzed vernakalant's efficacy [106]. ACT I, II, and III were randomized clinical studies and ACT IV was an open-label study of cardioversion with vernakalant. ACT I and III looked at patients who also had atrial flutter while ACT II looked at patients after major cardiac surgery. In ACT I, vernakalant's AF conversion rate was $51.7 \%$ compared 
to $4 \%$ in the placebo arm. In ACT III, it was $51.2 \%$ compared to placebo's $3.6 \%$. In ACT IV, vernakalant cardioverted $47 \%$ of the patients. However, ACT I and ACT III also demonstrated that the drug was not as effective in patients who had AF for more than 7 days. In these patients, only $8 \%$ were cardioverted in ACT I and $9 \%$ in ACT III. Vernakalant continues to be further investigated including a phase II a study examining an oral form of the drug.

Other ARDAs include XEN-DO101, AVE0118, and AZD7009. Rivard et al. and Shiroshita-Takeshita et al. have studied the effects of XEN-DO101, a highly selective inhibitor of the Kv1.5 channel, in dogs $[107,108]$. Their work has resulted in further investigations that plan to shed light on this compound's ability to maintain sinus rhythm after cardioversion in patients with persistent AF. AVE0118 has been studied in goat models and has been shown to prolong the atrial effective refractory period and cardiovert AF [109]. De Haan et al. also studied the drug's effects in goats and discovered that AVE0118 not only restores sinus rhythm but also improves atrial contractility [110]. Carlsson et al. investigated AZD7009 in canine models and illuminated the drug's selective actions in the atria over the ventricles [108]. Lofberg et al. also showed that AZD7009 can increase atrial refractoriness, suppress AF inducibility, and also rapidly convert AF [111]. This preliminary work resulted in a larger study in humans where 122 patients with AF or atrial flutter of at least 2 days duration were enlisted [112]. AZD7009 was shown to restore sinus rhythm in $45 \%$ $58 \%$ of the patients within 1 hour following the start of infusion. Despite these promising investigations, the extra-cardiac side effects of AZD7009 along with the high potential to prolong the QT interval have limited its potential clinical use.

\subsubsection{Class I Agents}

Novel Class I anti-arrhythmic agents that block sodium channels include pilsicainide and ranolazine. Okishige et $a l$. studied the effects of pilsicainide in patients with AF [113]. Subjects with recent-onset AF displayed a conversion rate of $45 \%$ within 90 minutes, compared to $8.6 \%$ for the placebo group. However, no advantage was apparent for pilsicainide in comparison to other class I anti-arrhythmic agents. Ranolazine is an anti-anginal agent that is also a strong inhibitor of the late sodium current [114]. Research in canine models has shown that sodium channel characteristics differ between atrial and ventricular cells and that ranolazine has a greater affinity for the atrial sodium channels [115]. Burashnikov et al. demonstrated the potential of ranolazine to terminate $\mathrm{AF}$ in canine models during acetylcholine infusion and during ischemia. This investigation has resulted in the plan- ning of a phase III trial to examine the effects of ranolazine in patients with AF.

\subsubsection{Calcium Channel Modifying Agents}

Not only are different derivatives of the already established classes of anti-arrhythmics being researched but also there are novel mechanisms being investigated as potential targets for new anti-arrhythmic medications. Agents that target pathophysiological mechanisms of AF are in development, including drugs that control calcium concentrations, drugs that modify the gap junction, and drugs that work at the atrial substrate.

Schlotthauer et al. and Chen et al. reported that increases in intracellular calcium concentrations promote delayed and late phase III early after-depolarizations that can induce ectopic activation, resulting in AF initiation [116,117]. Ryanodine receptors, channels that release calcium from the sarcoplasmic reticulum, respond to small increases in intracellular calcium concentrations and in turn, release their calcium stores and further increase the intracellular concentration. Canine models of $\mathrm{AF}$ induced by rapid right atrial pacing have recently shown that alterations in regulation and function of the ryanodine receptors in the heart result in hyperphosphorylation of the channel and depletion of calstabin 2 [118]. Calstabin 2 normally binds to the ryanodine receptors and decreases its open probability [119]. Thus, theoretically enhancing calstabin 2 levels can serve to reduce calcium leak from the sarcoplasmic reticulum and thereby, keep intracellular calcium concentrations low and prevent ectopic triggers of AF. Kumagai et al. and Chen et al. applied this theory in a canine sterile pericarditis model and results indicated that JTV-519, which acts by enhancing the affinity of calstabin 2 for ryanodine receptors, suppresses the inducibility of sustained $\mathrm{AF}$ and shortens the duration of induced atrial flutter $[120,121]$.

\subsubsection{Gap Junction Modifying Agents}

Cardiac gap junction channels are responsible for the propagation of the action potential in the heart. Connexins that make up the channel have specific forms in the cardiac tissue: Connexin 40 in the atrial myocardium and conduction tissue and connexin 45 found only in the conduction tissue. Firouzi et al. discovered the link between connexin 40 abnormalities and enhanced atrial vulnerability resulting in an increased risk of AF [122]. One of the first gap junction modifiers, called anti-arrhythmic peptide, was discovered in bovine hearts in 1980 and a synthetic peptide was developed in 1994 [123]. However, Weng et al. noted that the peptide was too unstable to be applied in clinical settings [124]. Rotigaptide was also derived from the original anti-arrhythmic peptide with a D-isomer substituted for a L- 
isomer. In rat models, the drug prevented metabolic stress-induced decrease in atrial conduction in isolated left atrial tissue but did not have an effect in physiological conditions [125]. In canine models of acute myocardial ischemia and mitral insufficiency, rotigaptide blocked induction of AF by inhibiting the slowing of conduction but had no effect on the atrial effective refractory period [126,127]. Lastly, GAP-134 was developed specifically for AF treatment and was investigated by Rossman et al [128]. The investigation used a canine sterile pericarditis model and results showed that GAP-134 successfully suppressed induction of AF. While research has picked up in recent years regarding cardiac gap junction channels as a potential target for anti-arrhythmic agents, there are growing concerns that modulating the action potential circuitry of the heart could destabilize re-entry pathways and be pro-arrhythmic.

\subsubsection{Anti-fibrosis Agents}

Lastly, drugs that target AF substrates also focus on finding treatable mechanisms within the pathophysiology of AF. Pirfenidone is an anti-fibrotic agent that inhibits collagen synthesis, blocks cytokine-induced fibroblast proliferation, and downregulates production of pro-fibrotic cytokines. In a canine model of heart failure induced by rapid ventricular pacing, pirfenidone was successful in attenuating left atrial fibrosis [129]. This effect resulted in a decrease in dispersion of repolarization, a reduction in the conduction heterogeneity index, and an overall decrease in AF vulnerability.

\section{NOVEL THERAPY- NONPHARMACOLOGICAL}

While new pharmacological therapies are being investigated to treat AF, so are surgical strategies. Schauerte et al. examined the pathophysiology of the vagal trigger of AF along with investigating the potential to denervate the vagal pathways in an attempt to treat paroxysmal AF [130]. The study looked at 11 dogs and found 7 of them to have localized atria sites following vagal nerve stimulation. This vagal stimulation served to shorten the atrial effective refractory period in each of the 7 sites, which was similar to effects seen in previous studies done in rabbits by Smeets et al. [131]. A shortened atrial effective refractory period leads to a decrease in the wavelength of atrial excitation wave fronts. With this shorter wavelength, there is a greater chance for reentry circuits to exist in the atrial myocardium, thus contributing to the increased potential for AF to occur [132]. In the 7 dogs with localized atrial sites, catheter RFA was performed on the parasympathetic pathways, decreasing the amount of shortened refractory periods. In fact, an increase of the baseline atrial effective refractory period was seen by roughly 4 milliseconds. Following the ablation, AF was no longer capable of being induced by vagal nerve stimulation. This investigation sets the stage for further animal studies and eventual human studies regarding atrial denervation and its potential to treat paroxysmal AF.

A small experimental study done in 2006 by Scanavacca et al. evaluated the potential effectiveness of treating AF by selective RFA of atrial sites where highfrequency stimulation induced vagal reflexes [133]. The theories elicited from Schauerte et al.'s canine study were applied to a subset of ten patients who had experienced vagal-induced paroxysmal AF. Vagal reflex was measured by an AV block for longer than 2 seconds and was induced by high-frequency transcatheter stimulation. This vagal response was seen in 7 out of 10 patients with the 7 subjects having an average of 5 atrial sites that displayed vagal reflexes. The most common epicardial sites were the left atrial posterior wall and near the right inferior pulmonary vein. The most common endocardial site was in between the right inferior pulmonary vein and left atrium. However, out of these 7 patients who had positive vagal responses to the high frequency stimulation and subsequently underwent RF ablation at these sites, only 2 individuals remained symptom-free at follow-up. Four suffered from frequent recurrences of $\mathrm{AF}$ in the first week while 1 patient had AF recurrences beginning at 4 months post-procedure. The most likely reasoning for this recurrence is that the elimination of the ganglia and vagal fibers was not completely effective. While Armour et al. adequately outlined the anatomic distribution of autonomic ganglionated plexus of the atria, there still is a possibility that selectively ablating the vagal innervations on the atria cannot be performed without a simultaneous ablation of all the sympathetic fibers that are also involved in the neuronal network. Additional limitations of this study include the small number of patients who were selected based on specific characteristics of their AF episodes. These qualities were episodes of AF occurring during sleep and rest, after meals, or after vasovagal syncope. This criteria may not be representative of patients who are suffering from paroxysmal AF induced by the vagus nervous system. Nevertheless, two patients remained AF-free and displayed obvious autonomic changes in their cardiovascular system. This investigation proved to be additionally valuable because it was the first study to evaluate the lone effects of atrial denervation on treatment of AF while previous studies done by Nakagawa et al. and Pappone et al. had looked at adjunctive vagal denervation during pulmonary vein isolation procedures $[134,135]$.

\section{NOVEL THERAPY-GENETICS}

In 2004, investigators from the Framingham Heart Study described an increased risk of AF in offspring in whom at least 1 parent had AF, even after factoring in estab- 
lished AF risk factors of hypertension, diabetes mellitus, and cardiovascular disease. Offspring who had at least 1 parent with AF had an almost two-fold increased risk of AF compared to the offspring who did not have a parental history of AF. Additionally, the correlation was even stronger when looking at offspring who had parents with AF that developed before 75 years of age [136]. In another study in Iceland, an increased risk of AF was seen among relatives who had an affected family member [137]. Moreover, with each successive degree of relation from the affected individual, the risk of AF decreased, clearly delineating a genetic component to the disease. Lone AF has also been recently studied and has been shown to have greater heritability than AF that is observed in the presence of cardiovascular or systemic disease. Studies done at Mayo Clinic exhibited a family history of AF in $15 \%$ of individuals who are first- or second-degree relatives of those with AF [138]. In the Massachusetts General Hospital AF study, investigators noted familial aggregation of $\mathrm{AF}$ in relatives of patients with AF [139]. Additionally, a twins study from Denmark has estimated the heritability of AF to be approximately $62 \%$ [140].

A 2003 investigation examined the mutation of the KCNQ1 gene in a family with AF, long QT syndrome and dilated cardiomyopathy [141]. The KCNQ1 potassium channel is the driving force behind the potassium current in myocytes. This 2003 investigation that noted a mutation in the KCNQ1 ion channel motivated other investigators to examine the roles of additional channels that are intricately involved in the atrial action potential. These studies have lead to the discovery of mutations in a number of potassium and sodium channels, gap junction proteins, and the atrial natriuretic peptide [142-144]. Research from the last 5 to 10 years has begun to illuminate the fact that AF is heritable. This concept alone has motivated efforts to search for genetic variations underlying AF, and the discovery of the role of novel genes and pathways is imminent.

\section{CONCLUSIONS}

AF is associated with morbidity and mortality as well as extremely high health care costs mentioned above. Therefore, potential mechanisms for the prevention of AF have a significant amount of public health importance [145].

The introduction of new treatment options for AF will continue to revolutionize how the disease is managed. Investigational studies of new drugs as well as innovative procedures will continue to propel the field and optimum treatment methods will soon be established. While novel therapies such as dabigatran and dronedarone have already been introduced into clinical practice, other pharmacological options are on the cusp of further utilization. Additionally, many of the innovative surgical procedures will continue to be investigated, adverse effects analyzed, and potentially put into practice as successful options for the treatment of AF. While the disease can be a debilitating one that is often difficult to manage and creates a poor quality of life for the patient, it is one that has been greatly studied in recent years. Recent research of AF can help expand our currently limited understanding of the pathophysiology of AF. Investigations from the past several years have proven valuable in establishing the potential causes of AF, including the fact that AF has a heritable component. With this knowledge, researchers can add to the understanding of AF by taking a closer look at the genetic variants involved with the disease. Additionally, identifying the genetic susceptibility loci of AF will lead to an improved understanding of the mechanisms and pathways involved in AF that can directly result in new targets for disease prevention. If the etiology of AF can be better understood, then further discoveries can not only lead to improved prevention and treatment possibilities but also improved risk stratification and prediction of the effectiveness of therapies. AF prevention can stand as a new avenue of potential therapy strategies. In the upcoming years, with abundant resources focused on investigating the etiology of the disease, the pathophysiology of the disease, as well as the mechanisms behind potential therapeutic options, patients suffering from AF will hopefully be able to change the way the disease effects their lives and patients who may potentially be predisposed to AF will hopefully be prevented of obtaining the disease as a whole.

\section{REFERENCES}

[1] Miyasaka, Y., Barnes, M.E., Gersh, B.J., Cha, S.S., Bailey, K.R., Abhayaratna, W.P., et al. (2006) Secular trends in incidence of atrial fibrillation in Olmsted county, Minnesota, 1980 to 2000, and implications on the projections for future prevalence. Circulation, 114,119-125. doi:10.1161/CIRCULATIONAHA.105.595140

[2] Lloyd-Jones, D.M., Wang, T.J., Leip, E.P., Larson, M.G., Levy, D., Vasan, R.S., et al. (2004) Lifetime risk for development of atrial fibrillation: The Framingham heart study. Circulation, 110, 1042-1046. doi:10.1161/01.CIR.0000140263.20897.42

[3] Stewart, S., Hart, C.L., Hole, D.J. and McMurray, J.J. (2002) A population-based study of the long-term risks associated with atrial fibrillation: 20-year follow-up of the renfrew/paisley study. American Journal of Medicine, 113, 359-364. doi:10.1016/S0002-9343(02)01236-6

[4] Kannel, W.B., Wolf, P.A., Benjamin, E.J. and Levy, D. (1998) Prevalence, incidence, prognosis, and predisposing conditions for atrial fibrillation: Population-based estimates. American Journal of Cardiology, 82, 2N-9N. doi:10.1016/S0002-9149(98)00583-9

[5] Wattigney, W.A., Mensah, G.A. and Croft, J.B. (2003) 
Increasing trends in hospitalization for atrial fibrillation in the United States, 1985 through 1999: Implications for primary prevention. Circulation, 108, 711-716. doi:10.1161/01.CIR.0000083722.42033.0A

[6] Benjamin, E.J., Levy, D., Vaziri, S.M., D’Agostino, R.B., Belanger, A.J. and Wolf, P.A. (1994) Independent risk factors for atrial fibrillation in a population-based cohort. The Framingham heart study. JAMA, 271, 840-844. doi:10.1001/jama.1994.03510350050036

[7] Psaty, B.M., Manolio, T.A., Kuller, L.H., Kronmal, R.A., Cushman, M., Fried, L.P., et al. (1997) Incidence of and risk factors for atrial fibrillation in older adults. Circulation, 96, 2455-2461.

doi:10.1161/01.CIR.96.7.2455

[8] Natale, A., Raviele, A., Arentz, T., Calkins, H., Chen, S.A., Haissaquerre, M., et al. (2007) Venice chart international consensus document on atrial fibrillation ablation. Journal of Cardiovascular Electrophysiology, 18, 560-580. doi:10.1111/j.1540-8167.2007.00816.x

[9] Pappone, C., Santinelli, V., Manguso, F., Vicedomini, G., Gugliotta, F., Augello, G., et al. (2004) Pulmonary vein denervation enhances long-term benefit after circumferential ablation for paroxysmal atrial fibrillation. Circulation, 109,327-334. doi:10.1161/01.CIR.0000112641.16340.C7

[10] Fuster, V., Ryden, L.E., Cannom, D.S., Crijns, H.K., Curtis, A.B., Ellenbogen, K.A., et al. (2006) ACC/AHA/ ESC 2006 Guidelines for the management of patients with atrial fibrillation a report of the American College of Cardiology/American Heart Association task force on practice guidelines and the European society of cardiology committee for practice guidelines (writing committee to revise the 2001 guidelines for the management of patients with atrial fibrillation). Journal of the American College of Cardiology, 48, e149. doi:10.1016/j.jacc.2006.07.018

[11] Gage, B.F., Waterman, A.D., Shannon, W., Boechler, M., Rich, M.W. and Radford, M.J. (2001) Validation of clinical classification schemes for predicting stroke: Results from the National Registry of Atrial Fibrillation. JAMA, 285, 2864-2870. doi:10.1001/jama.285.22.2864

[12] Man-Son-Hing, M., Laupacis, A., O’Connor, A.M., Biggs, J., Drake, E., Yetisir, E., et al. (1999) A patient decision aid regarding antithrombotic therapy for stroke prevention in atrial fibrillation: A randomized controlled trial. JAMA, 282, 737. doi:10.1001/jama.282.8.737

[13] ACTIVE Investigators, Connolly, S.J., Pogue, J., Hart, R.G., Hohnloser, S.H., Pfeffer, M., Chrolavicius, S., et al. (2009) Effect of clopidogrel added to aspirin in patients with atrial fibrillation. The New England Journal of Medicine, 360, 2066. doi:10.1056/NEJMoa0901301

[14] Cairns, J.A. (1991) Stroke prevention in atrial fibrillation study. Final results. Circulation, 84, 527. doi:10.1161/01.CIR.84.2.933

[15] Hart, R.G., Pearce, L.A. and Aguilar, M.I. (2007) Meta-analysis: Antithrombotic therapy to prevent stroke in patients who have nonvalvular atrial fibrillation. Annals of Internal Medicine, 146, 857.

[16] Singer, D.E., Albers, G.W., Dalen, J.E., Fang, M.C., Go,
A.S., Halperin, J.L., et al. (2008) Antithrombotic therapy in atrial fibrillation: American College of chest physicians evidence-based clinical practice guidelines (8th Edition) Chest, 133, 546S.

[17] Hylek, E.M., Go, A.S., Chang, Y., Jensvold, N.J., Henault, L.E., Selby, J.V., et al. (2003) Effect of intensity of oral anticoagulation on stroke severity and mortality in atrial fibrillation. The New England Journal of Medicine, 349, 1019. doi:10.1056/NEJMoa022913

[18] Olshansky, B., Rosenfeld, L.E., Warner, A.L., Solomon, A.J., O’Neill, G., Sharma, A., et al. (2004) The atrial fibrillation follow-up investigation of rhythm management (AFFIRM) study: Approaches to control rate in atrial fibrillation. Journal of the American College of Cardiology, 43, 1201-1208. doi:10.1016/j.jacc.2003.11.032

[19] Wyse, D.G., Waldo, A.L., DiMarco, J.P., Domanski, M.J., Rosenberg, Y., Schron, E.B., et al. (2002) A comparison of rate control and rhythm control in patients with atrial fibrillation. The New England Journal of Medicine, 347, 1825. doi:10.1056/NEJMoa021328

[20] Steinberg, J.S., Sadaniantz, A., Kron, J., Krahn, A., Denny, D.M., Daubert, J., et al. (2004) Analysis of causespecific mortality in the atrial fibrillation follow-up investtigation of rhythm management (AFFIRM) study. Circulation, 109, 1973. doi:10.1161/01.CIR.0000118472.77237.FA

[21] Van Gelder, I.C., Hagens, V.E., Bosker, H.A., Kingma, J.H., Kamp, O., Kingma, T., et al. (2002) A comparison of rate control and rhythm control in patients with recurrent persistent atrial fibrillation. The New England Journal of Medicine, 347, 1834. doi:10.1056/NEJMoa021375

[22] Fuster, V., Rydén, L.E., Cannom, D.S., Crijns, H.J., Curtis, A.B., Ellenbogen, K.A., et al. (2006) ACC/AHA/ ESC 2006 Guidelines for the management of patients with atrial fibrillation: A report of the American College of Cardiology/American Heart Association Task Force on Practice Guidelines and the European Society of Cardiology Committee for practice guidelines (Writing Committee to revise the 2001 guidelines for the management of patients with atrial fibrillation): Developed in collaboration with the European Heart Rhythm Association and the Heart Rhythm Society. Circulation, 114, 257-354. doi:10.1161/CIRCULATIONAHA.106.177292

[23] Connolly, S.J. (2000) Appropriate outcome measures in trials evaluating treatment of atrial fibrillation. American Heart Journal, 139, 752 doi:10.1016/S0002-8703(00)90002-4

[24] Lafuente-Lafuente, C., Mouly, S., Longas-Tejero, M.A. and Bergmann, J.F. (2006) Antiarrhythmic drugs for maintaining sinus rhythm after cardioversion of atrial fibrillation: A systematic review of randomized controlled trials. Archives of Internal Medicine, 166, 719. doi:10.1001/archinte.166.7.719

[25] Chimienti, M., Cullen, M.T.Jr. and Casadei, G. (1996) Safety of long-term flecainide and propafenone in the management of patients with symptomatic paroxysmal atrial fibrillation: Report from the flecainide and propafenone Italian study investigators. American Journal of Cardio- 
logy, 77, 60A. doi:10.1016/S0002-9149(97)89119-9

[26] Schumacher, B., Jung, W., Lewalter, T., Vahlhaus, C., Wolper, C. and Luderitz, B. (1999) Radiofrequency ablation of atrial flutter due to administration of class IC antiarrhythmic drugs for atrial fibrillation. American Journal of Cardiology, 83, 710-713. doi:10.1016/S0002-9149(98)00975-8

[27] Echt, D.S., Liebson, P.R., Mitchell, L.B., Peters, R.W., ObiasManno, D., Barker, A.H., et al. (1991) Mortality and morbidity in patients receiving encainide, flecainide, or placebo. The Cardiac Arrhythmia Suppression Trial. The New England Journal of Medicine, 324, 781-788. doi:10.1056/NEJM199103213241201

[28] McNamara, R.L., Tamariz, L.J., Segal, J.B. and Bass, E.B. (2003) Management of atrial fibrillation: Review of the evidence for the role of pharmacologic therapy, electrical cardioversion, and echocardiography. Annals of Internal Medicine, 139, 1018-1033.

[29] Singh, S., Zoble, R.G., Yellen, L., Brodsky, M.A., Feld, G.K., Berk, M., et al. (2000) Efficacy and safety of oral dofetilide in converting to and maintaining sinus rhythm in patients with chronic atrial fibrillation or atrial flutter: The symptomatic atrial fibrillation investigative research on dofetilide (SAFIRE-D) study. Circulation, 102, 23852390. doi:10.1161/01.CIR.102.19.2385

[30] Mounsey, J.P. and DiMarco, J.P. (2000) Cardiovascular drugs. Dofetilide. Circulation, 102, 2665-2670. doi:10.1161/01.CIR.102.21.2665

[31] Castro, A., Bianconi, L. and Santini, M. (2002) New antiarrhythmic drugs for the treatment of atrial fibrillation. Pacing and Clinical Electrophysiology, 25, 249-259. doi:10.1046/j.1460-9592.2002.00249.X

[32] Gallik, D.M., Kim, S.G., Ferrick, K.J., Roth, J.A. and Fisher, J.D. (1997) Efficacy and safety of sotalol in patients with refractory atrial fibrillation or flutter. American Heart Journal, 134, 155. doi:10.1016/S0002-8703(97)70118-2

[33] Boersma, L.V., Castella, M., van Boven, W., Berruezo, A., Yilmaz, A., Nadal, M., et al. (2012) Atrial fibrillation catheter ablation versus surgical ablation treatment (FAST): A 2-center randomized clinical trial. Circulation, 125, 23-30. doi:10.1161/CIRCULATIONAHA.111.074047

[34] Ferguson, T.B.Jr. and Cox, J.L. (1995) Surgery for atrial fibrillation. In: Zipes, D.P. and Jalife, J., Eds., Cardiac Electrophysiology: From Cell to Bedside, 2nd Editon, Saunders, Philadelphia, 1567.

[35] Cox, J.L., Canavan, T.E., Schuessler, R.B., Cain, M.E., Lindsay, B.D., Stone, C., et al. (1991) The surgical treatment of atrial fibrillation. II. Intraoperative electrophysiologic mapping and description of the electrophysiologic basis of atrial flutter and atrial fibrillation. The Journal of Thoracic and Cardiovascular Surgery, 101, 406.

[36] Lönnerholm, S., Blomström, P., Nilsson, L., Oxelbark, S., Jideius, L. and Blomstrom-Lundqvist, C. (2000) Effects of the maze operation on health-related quality of life in patients with atrial fibrillation. Circulation, 101, 2607. doi:10.1161/01.CIR.101.22.2607

[37] Cox, J.L., Boineau, J.P., Schuessler, R.B., Kater, K.M. and Lappas, D.G. (1993) Five-year experience with the maze procedure for atrial fibrillation. The Annals of Thoracic Surgery, 56, 814. doi:10.1016/0003-4975(93)90338-I

[38] Gaynor, S.L., Schuessler, R.B., Bailey, M.S., Ishii, Y., Boineau, J.P., Gleva, M.J., et al. (2005) Surgical treatment of atrial fibrillation: Predictors of late recurrence. The Journal of Thoracic and Cardiovascular Surgery, 129, 104. doi:10.1016/j.jtcvs.2004.08.042

[39] Sandoval, N., Velasco, V.M., Orjuela, H., Caicedo, V., Santos, H., Rosas, F., et al. (1996) Concomitant mitral valve or atrial septal defect surgery and the modified Coxmaze procedure. American Journal of Cardiology, 77, 591. doi:10.1016/S0002-9149(97)89312-5

[40] Pasic, M., Musci, M., Siniawski, H., Grauhan, O., Edelmann, B., Tedoriya, T., et al. (1999) The Cox maze iii procedure: parallel normalization of sinus node dysfunction, improvement of atrial function, and recovery of the cardiac autonomic nervous system. The Journal of Thoracic and Cardiovascular Surgery, 118, 287. doi:10.1016/S0022-5223(99)70219-9

[41] Nitta, T., Lee, R., Schuessler, R.B., Boineau, J.P. and Cox, J.L. (1999) Radial approach: A new concept in surgical treatment for atrial fibrillation I. Concept, anatomic and physiologic bases and development of a procedure. The Annals of Thoracic Surgery, 67, 27. doi:10.1016/S0003-4975(98)01364-2

[42] Nitta, T., Lee, R., Watanabe, H., Harris, K.M., Erikson, J.M., Schuessler, R.B., et al. (1999) Radial approach: A new concept in surgical treatment for atrial fibrillation. II. Electrophysiologic effects and atrial contribution to ventricular filling. The Annals of Thoracic Surgery, 67, 36. doi:10.1016/S0003-4975(98)01365-4

[43] Nitta, T., Ishii, Y., Ogasawara, H., Sakamoto, S., Miyagi, Y., Yamada, K., et al. (1999) Initial experience with the radial incision approach for atrial fibrillation. The Annals of Thoracic Surgery, 68, 805. doi:10.1016/S0003-4975(99)00775-4

[44] Leitch, J.W., Klein, G., Yee, R. and Guiraudon, G. (1991) Sinus node-atrioventricular node isolation: Long-term results with the "corridor" operation for atrial fibrillation. Journal of the American College of Cardiology, 17, 970. doi:10.1016/0735-1097(91)90881-9

[45] Haissaguerre, M., Jais, P., Shah, D.C., Takahashi, A., Hocini, M., Quiniou, G., et al. (1998) Spontaneous initiation of atrial fibrillation by ectopic beats originating in the pulmonary veings. The New England Journal of Medicine, 339, 659. doi:10.1056/NEJM199809033391003

[46] Sueda, T., Imai, K., Ishii, O., Orihashi, K., Watari, M. and Okada, K. (2001) Efficacy of pulmonary vein isolation for the elimination of chronic atrial fibrillation in cardiac valvular surgery. The Annals of Thoracic Surgery, 71, 1189. doi:10.1016/S0003-4975(00)02606-0

[47] Krul, S.P., Driessen, A.H., van Boven, W.J., Linnenbank, A.C., Geuzebroek, G.S., Jackman, W.M., et al. (2011) Thoracoscopic video-assisted pulmonary vein antrum isolation, ganglionated plexus ablation, and periproce- dural confirmation of ablation lesions: First results of a hybrid surgical-electrophysiological approach for atrial fibrillation. Circulation: Arrhythmia and Electrophysiology, 4, 
262.

[48] Cheema, A., Dong, J., Dalal, D., Marine, J.E., Henrikson, C.A., Spragg, D., et al. (2007) Circumferential ablation with pulmonary vein isolation in permanent atrial fibrillation. American Journal of Cardiology, 99, 1425. doi:10.1016/j.amjcard.2006.12.073

[49] Hocini, M., Jaïs, P., Sanders, P., Takahashi, Y., Rotter, M., Rostock, T., et al. (2005) Techniques, evaluation, and consequences of linear block at the left atrial roof in paroxysmal atrial fibrillation: A prospective randomized study. Circulation, 112, 3688. doi:10.1161/CIRCULATIONAHA.105.541052

[50] Oral, H., Scharf, C., Chugh, A., Hall, B., Cheung, P., Good, E., et al. (2003) Catheter ablation for paroxysmal atrial fibrillation: Segmental pulmonary vein ostial ablation versus left atrial ablation. Circulation, 108, 2355. doi:10.1161/01.CIR.0000095796.45180.88

[51] Karch, M.R., Zrenner, B., Deisenhofer, I., Schreieck, J., Ndrepepa, G., Dong, J., et al. (2005) Freedom from atrial tachyarrhythmias after catheter ablation of atrial fibrillation: a randomized comparison between 2 current ablation strategies. Circulation, 111, 2875. doi:10.1161/CIRCULATIONAHA.104.491530

[52] Pappone, C., Oral, H., Santinelli, V., Vicedomini, G., Lang, C.C., Manguso, F., et al. (2004) Atrio-esophageal fistula as a complication of percutaneous transcatheter ablation of atrial fibrillation. Circulation, 109, 2724. doi:10.1161/01.CIR.0000131866.44650.46

[53] Shah, D., Dumonceau, J.M., Burri, H., Sunthorn, H., Schroft, A., Gentil-Baron, P., et al. (2005) Acute pyloric spasm and gastric hypomotility: An extracardiac adverse effect of percutaneous radiofrequency ablation for atrial fibrillation. Journal of the American College of Cardiology, 46, 327-330. doi:10.1016/j.jacc.2005.04.030

[54] Oral, H., Knight, B.P., Ozaydin, M., Tada, H., Chugh, A., Hassan, S., et al. (2002) Clinical significance of early recurrences of atrial fibrillation after pulmonary vein isolation. Journal of the American College of Cardiology, 40, 100. doi:10.1016/S0735-1097(02)01939-3

[55] Lubitz, S.A., Fischer, A. and Fuster, V. (2008) Catheter ablation for atrial fibrillation. BMJ, 336, 819. doi:10.1136/bmj.39513.555150.BE

[56] Gerstenfeld, E.P., Callans, D.J., Dixit, S., Zado, E. and Marchlinski, F.E. (2003) Incidence and location of focal atrial fibrillation triggers in patients undergoing repeat pulmonary vein isolation: Implications for ablation strategies. Journal of Cardiovascular Electrophysiology, 14, 685. doi:10.1046/j.1540-8167.2003.03013.x

[57] Chen, S.A. and Tai, C.T. (2005) Catheter ablation of atrial fibrillation originating from the non-pulmonary vein foci. Journal of Cardiovascular Electrophysiology, 16, 229. doi:10.1046/j.1540-8167.2005.40665.x

[58] Di Biase, L., Burkhardt, J.D., Mohanty, P., Sanchez, J., Mohanty, S., Horton, R., et al. (2010) Left atrial appendage: An underrecognized trigger site of atrial fibrillation. Circulation, 122, 109. doi:10.1161/CIRCULATIONAHA.109.928903

[59] Van Belle, Y., Janse, P., et al. (2007) Pulmonary vein iso- lation using an occluding cryoballoon for circumferential ablation: Feasibility, complications, and short-term outcome. European Heart Journal, 28, 2231-2237. doi:10.1093/eurheartj/ehm227

[60] Neumann, T., Vogt, J., Schumacher, B., Dorszewski, A., Kuniss, M., Neuser, H., et al. (2008) Circumferential pulmonary vein isolation with the cryoballoon technique results from a prospective 3-center study. Journal of the American College of Cardiology, 52, 273-278. doi:10.1016/j.jacc.2008.04.021

[61] Linhart, M., Bellman, B., Mittmann-Braun, E., Schrickel, J.W., Bitzen, A., et al. (2009) Comparison of cryoballoon and radiofrequency ablation of pulmonary veins in 40 patients with paroxysmal atrial fibrillation: A case-control study. Journal of Cardiovascular Electrophysiology, 20, 1-6

[62] Tintera, J., Porod, V., Cihak, R., Micochova, H., Rolencova, E., Fendrych, P., et al. (2006) Assessment of pulmonary venous stenosis after radiofrequency catheter ablation for atrial fibrillation by magnetic resonance angiography: A comparison of linear and cross-sectional area measurements. European Radiology, 16, 2757-2767. doi:10.1007/s00330-006-0358-3

[63] Zhou, J.M., Liu, S.W., Lin, J.X., Nie, Z.N., Wu, H.Y., Zhou, J., et al. (2007) Thromboembolic event rate in patients with persistent or paroxysmal atrial fibrillation post circumferential pulmonary vein isolation: A single center experience in China. Chinese Medical Journal, 120, 956959.

[64] Curtis, A.B., Kutalek, S.P., Prior, M. and Newhouse, T.T. (2000) Prevalence and characteristics of escape rhythms after radiofrequency ablation of the atrioventricular junction: Results from the registry for AV junction ablation and pacing in atrial fibrillation. Ablate and Pace Trial Investigators. American Heart Journal, 139, 122. doi:10.1016/S0002-8703(00)90318-1

[65] Scheinman, M.M. and Huang, S. (2000) The 1998 NASPE prospective catheter ablation registry. Pacing and Clinical Electrophysiology, 23, 1020. doi:10.1111/j.1540-8159.2000.tb00891.x

[66] Wood, M.A., Brown-Mahoney, C., Kay, G.N. and Ellenbogen, K.A. (2000) Clinical outcomes after ablation and pacing therapy for atrial fibrillation: A meta-analysis. Circulation, 101, 1138. doi:10.1161/01.CIR.101.10.1138

[67] Ozcan, C., Jahangir, A., Friedman, P.A., Patel, P.J., Munger, T.M., Rea, R.F., et al. (2001) Long-term survival after ablation of the atrioventricular node and implantation of a permanent pacemaker in patients with atrial fibrillation. The New England Journal of Medicine, 344, 1043. doi:10.1056/NEJM200104053441403

[68] Ozcan, C., Jahangir, A., Friedman, P.A., Hayes, D.L., Munger, T.M., Rea, R.F., et al. (2002) Sudden death after radiofrequency ablation of the atrioventricular node in patients with atrial fibrillation. Journal of the American College of Cardiology, 40, 105. doi:10.1016/S0735-1097(02)01927-7

[69] Geelen, P., Brugada, J., Andries, E. and Brugada, P. (1997) Ventricular fibrillation and sudden death after radio-frequency catheter ablation of the atrioventricular junction. 
Pacing and Clinical Electrophysiology, 20, 343. doi:10.1111/j.1540-8159.1997.tb06179.x

[70] Marshall, H.J., Harris, Z.I., Griffith, M.J., Holder, R.L. and Gammage, M.D. (1999) Prospective randomized study of ablation and pacing versus medical therapy for paroxysmal atrial fibrillation: Effects of pacing mode and mode- switch algorithm. Circulation, 99, 1587.

doi:10.1161/01.CIR.99.12.1587

[71] Williamson, B.D., Man, K.C., Daoud, E., Niebauer, M., Strickberger, S.A. and Morady, F. (1994) Radiofrequency catheter modification of atrioventricular conduction to control the ventricular rate during atrial fibrillation. The New England Journal of Medicine, 331, 910. doi:10.1056/NEJM199410063311404

[72] Della Bella, P., Carbucicchio, C., Tondo, C. and Riva, S. (1995) Modulation of atrioventricular conduction by ablation of the "slow" atrioventricular node pathway in patients with drug-refractory atrial fibrillation or flutter. Journal of the American College of Cardiology, 25, 39. doi:10.1016/0735-1097(94)00315-H

[73] Proclemer, A., Della Bella, P., Tondo, C., Facchin, D., Carbucicchia, C., Riva, S., et al. (1999) Radiofrequency ablation of atrioventricular junction and pacemaker implantation versus modulation of atrioventricular conduction in drug refractory atrial fibrillation. Journal of the American College of Cardiology, 83, 1437. doi:10.1016/S0002-9149(99)00121-6

[74] Mant, J., Hobbs, F.D., Fletcher, K., Roalfe, A., Fitzmaurice, D., Lip, G.Y., et al. (2007) Warfarin versus aspirin for stroke prevention in an elderly community population with atrial fibrillation (the Birmingham Atrial Fibrillation Treatment of the Aged study, BAFTA): A randomised controlled trial. Lancet, 370, 493-503. doi:10.1016/S0140-6736(07)61233-1

[75] Connolly, S., Pogue, J., Hart, R., Pfeffer, M., Hohnloser, S., Chrolavicius, S., et al. (2006) Clopidogrel plus aspirin versus oral anticoagulation for atrial fibrillation in the Atrial fibrillation Clopidogrel Trial with Irbesartan for prevention of Vascular Events (ACTIVE W): A randomised controlled trial. Lancet, 367, 1903-1912. doi:10.1016/S0140-6736(06)68845-4

[76] Francis, C.W., Berkowitz, S.D., Comp, P.C., Liberman, J.R., Ginsberg, J.S., Paiment, G., the EXULT A Study Group, et al. (2003) Comparison of ximelagatran with warfarin for the prevention of venous thromboembolism after total knee replacement. The New England Journal of Medicine, 349, 1703-1712.

[77] Albers, G.W., Diener, H.C., Frison, L., Grind, M., Nevinson, M., Partridge, S., et al. (2005) Ximelagatran vs warfarin for stroke prevention in patients with nonvalvular atrial fibrillation: A randomized trial. JAMA, 293, 690- 698. doi:10.1001/jama.293.6.690

[78] Eriksson, B.I., Dahl, O.E., Huo, M.H., Kurth, A.A., Hantel, S., Harmansson, K., et al. (2010) Oral dabigatran versus enoxaparin for thromboprophylaxis after primary total hip arthroplasty (RE-NOVATE II*). A randomised, doubleblind, non-inferiority trial. Haematologica, 95, 721-729.

[79] Eriksson, B.I., Dahl, O.E., Rosencher, N., Kurth, A.A., van Dijk, C.N., Frostick, S.P., et al. (2007) Oral dabiga- tran etexilate vs. subcutaneous enoxaparin for the prevention of venous thromboembolism after total knee replacement: The RE-MODEL randomized trial. Journal of Thrombosis and Haemostasis, 5, 2178-2185. doi:10.1111/j.1538-7836.2007.02748.x

[80] Ezekowitz, M.D., Reilly, P.A., Nehmiz, G., Simmers, T.A., Nagarakanti, R., Parcham-Azad, K., et al. (2007) Dabigatran with or without concomitant aspirin compared with warfarin alone in patients with nonvalvular atrial fibrillation (PETRO Study). American Journal of Cardiology, 100, 1419-1426. doi:10.1016/j.amjcard.2007.06.034

[81] Connolly, S.J., Ezekowitz, M.D., Yusuf, S., Eikelboom, J., Oldgren, J., Parekh, A., et al. (2009) RE-LY Steering Committee and investigators dabigatran versus warfarin in patients with atrial fibrillation. The New England Journal of Medicine, 361, 1139-1151. doi:10.1056/NEJMoa0905561

[82] Eriksson, B.I., Borris, L.C., Friedman, R.J., Haas, S., Huisman, M.V., Kakkar, A.K., et al. (2008) Rivaroxaban versus enoxaparin for thromboprophylaxis after hip arthroplasty. The New England Journal of Medicine, 358, 27652775. doi:10.1056/NEJMoa0800374

[83] Becker, R., Berkowtiz, S.D., Breithardt, G., Califf, R.M., Fox, K., Hacke, W., et al. ROCKET AF Study Investigators (2010) Rivaroxaban-once daily, oral, direct factor Xa inhibition compared with vitamin $\mathrm{K}$ antagonism for prevention of stroke and embolism trial in atrial fibrillation: Rationale and design of the ROCKET AF study. American Heart Journal, 159, 340-347.

[84] Patel, M.R., Mahaffey, K.W., Garg, J., Pan, G., Singer, D.E., Hacke, W., et al. (2011) Rivaroxaban versus warfarin in nonvalvular atrial fibrillation. The New England Journal of Medicine, 365, 883. doi:10.1056/NEJMoa1009638

[85] Lassen, M.R., Raskob, G.E., Gallus, A., Pineo, G., Chen, D. and Portman, R.J. (2009) Apixaban or enoxaparin for thromboprophylaxis after knee replacement. The New England Journal of Medicine, 361, 594-604. doi:10.1056/NEJMoa0810773

[86] Lopes, R.D., Alexander, J.H., Al-Khatib, S.M., Ansell, J., Diaz, R., Easton, J.D., et al. (2010) Apixaban for reducetion in stroke and other thromboembolic events in atrial fibrillation (ARISTOTLE) trial: Design and rationale. American Heart Journal, 159, 331-339. doi:10.1016/j.ahj.2009.07.035

[87] Eikelboom, J.W., O’Donnell, M., Yusuf, S., Diaz, R., Flaker, G., Hart, R., et al. (2010) Rationale and design of AVERROES: Apixaban versus acetylsalicylic acid to prevent stroke in atrial fibrillation patients who have failed or are unsuitable for vitamin $\mathrm{K}$ antagonist treatment. American Heart Journal, 159, 348-353.

[88] Camm, A.J., Pratt, C.M., Schwartz, P.J., Al-Khalidi, H.R., Spyt, M.J., Holroyde, M.J., et al. (2004) Mortality in patients with recent myocardial infarction: A randomized, placebo-controlled trial of azimilide using heart rate variability for risk stratification. Circulation, 109, 990996. doi:10.1161/01.CIR.0000117090.01718.2A

[89] Kerr, C.R., Connolly, S.J., Kowey, P., Page, R.L., Pritch- 
ett, E.L., Ruda, M.Y., et al., A-STAR Investigators (2006) Efficacy of azimilide for the maintenance of sinus rhythm in patients with paroxysmal atrial fibrillation in the presence and absence of structural heart disease. American Journal of Cardiology, 98, 215-218. doi:10.1016/j.amjcard.2006.01.084

[90] Lombardi, F., Borggrefe, M., Ruzyllo, W., Luderitz, B., A-COMET-II Investigators (2006) Azimilide vs. placebo and sotalol for persistent atrial fibrillation: The A-COMETII (Azimilide-CardiOversionMaintEnance Trial-II) trial. European Heart Journal, 27, 2224-2231. doi:10.1093/eurheartj/ehl209

[91] Page, R.L., Pritchett, E.L., Connolly, S., Wilkinson, W.E., For the SVA-4 Investigators (2008) Azimilide for the treatment of atrial fibrillation, atrial flutter, and paroxysmal supraventricular tachycardia: Results of a randomized trial and insights on the concordance of symptoms and recurrent arrhythmias. Journal of Cardiovascular Electrophysiology, 19, 172-177. doi:10.1111/j.1540-8167.2007.00985.x

[92] Hohnloser, S.H., Dorian, P., Straub, M., Beckmann, K. and Kowey, P. (2004) Safety and efficacy of intravenously administered tedisamil for rapid conversion of recent-onset atrial fibrillation or atrial flutter. Journal of the American College of Cardiology, 44, 99-104. doi:10.1016/j.jacc.2004.03.047

[93] Morita, N., Tanaka, K., Yodogawa, K., Hayashi, M., Akutsu, K., Yamamoto, T., et al. (2007) Effect of nifekalant for acute conversion of atrial flutter: The possible termination mechanism of typical atrial flutter. Pacing and Clinical Electrophysiology, 30, 1242-1253. doi:10.1111/j.1540-8159.2007.00846.x

[94] Wegener, F.T., Ehrlich, J.R. and Hohnloser, S.H. (2006) Dronedarone: An emerging agent with rhythm- and ratecontrolling effects. Journal of Cardiovascular Electrophysiology, 17, 17-20. doi:10.1111/j.1540-8167.2006.00583.x

[95] Singh, B.N., Connolly, S.J., Crijns, H.J., Roy, D., Kowey, P.R., Capucci, A., et al., EURIDIS ADONIS Investigators (2007) Dronedarone for maintenance of sinus rhythm in atrial fibrillation or flutter. The New England Journal of Medicine, 357, 987-999. doi:10.1056/NEJMoa054686

[96] Davy, J.M., Herold, M., Radzik, D. and Timmermans, A.J.M. (2006) Effect of dronedarone on exercise in patients with permanent atrial fibrillation (Abstract). European Heart Journal, 27, 885.

[97] Connolly, S.J., Camm, A.J., Halperin, J.L., Joyner, C., Alings, M., Amerena, J., et al. (2011) Dronedarone in highrisk permanent atrial fibrillation. The New England Journal of Medicine, 365, 2268-2276. doi:10.1056/NEJMoa1109867

[98] Hohnloser, S.H., Connolly, S.J., Crijns, H.J., Page, R.L., Seiz, W. and Torp-Petersen, C. (2008) Rationale and design of ATHENA: A placebo-controlled, double-blind, parallel arm Trial to assess the efficacy of dronedarone $400 \mathrm{mg}$ bid for the prevention of cardiovascular Hospitalization or death from any cause in patients with atrial fibrillation/atrial flutter. Journal of Cardiovascular Electrophysiology, 19, 69-73.
[99] Gautier, P., Serre, M., Cosnier-Pucheu, S., Djandjighian, L., Roccon, A., Herbert, J.M., et al. (2005) In vivo and in vitro antiarrhythmic effects of SSR149744C in animal models of atrial fibrillation and ventricular arrhythmias. Journal of Cardiovascular Pharmacology, 45, 125-135. doi:10.1097/01.fjc.0000151899.03379.76

[100] Kowey, P.R., Aliot, E.M., Capucci, A., Connolly, S.J., Crijns, H.J., Hohnloser, S.H., et al. (2007) Placebo-controlled double-blind dose-ranging study of the efficacy and safety of SSR149744C in patients with recent atrial fibrillation/flutter (Abstract). Heart Rhythm, 4, S72.

[101] Arya, A., Silberbauer, J., Sulke, N. and Camm, A.J. (2006) A phase 2 pilot study of the efficacy of AT-2042 in subjects with paroxysmal atrial fibrillation and implanted pacemakers (Abstract). Heart Rhythm, 3, S164. doi:10.1016/j.hrthm.2006.02.488

[102] Nakashima, H., Gerlach, U., Schmidt, D. and Nattel, S. (2004) In vivo electrophysiological effects of a selective slow delayed-rectifier potassium channel blocker in anesthetized dogs: Potential insights into class III actions. Cardiovascular Research, 61, 651-652. doi:10.1016/j.cardiores.2003.12.016

[103] Blaauw, Y., Gogelein, H., Tieleman, R.G., van Hunnik, A., Schotten, U. and Allessie, M.A. (2004) "Early” class III drugs for the treatment of atrial fibrillation: Efficacy and atrial selectivity of AVE0118 in remodeled atria of the goat. Circulation, 110, 1717-1724. doi:10.1161/01.CIR.0000143050.22291.2E

[104] Wettwer, E. (2007) Is there a functional correlate of Kv1.5 in the ventricle of canine heart and what would it mean for the use of I(Kur) blockers? British Journal of Pharmacology, 152, 835-837. doi:10.1038/sj.bjp.0707463

[105] Roy, D., Rowe, B.H., Stiell, I.G., Coutu, B., Ip, J.H., Phaneuf, D., et al., CRAFT Investigators (2004) A randomized, controlled trial of RSD1235, a novel antiarrhythmic agent, in the treatment of recent onset atrial fibrillation. Journal of the American College of Cardiology, 44, 2355- 2361. doi:10.1016/j.jacc.2004.09.021

[106] Roy, D., Pratt, C.M., Torp-Pedersen, C., Wyse, D.G., Toft, E., Juul-Moller, S., et al., for the Atrial Arrhythmia Conversion Trial Investigators (2008) Vernakalant hydrochloride for rapid conversion of atrial fibrillation: A phase 3, randomized, placebo-controlled trial. Circulation, 117, 1518-1525. doi:10.1161/CIRCULATIONAHA.107.723866

[107] Rivard, L., Shiroshita-Takeshita, A., Maltais, C., Ford, J., Pinnock, R., Madge, D., et al. (2005) Electrophysiological and atrial antiarrhythmic effects of a novel IKur/ Kv1.5 blocker in dogs (Abstract). Heart Rhythm, 2, S180. doi:10.1016/j.hrthm.2005.02.561

[108] Shiroshita-Takeshita, A., Ford, J., Madge, D., Pinnock, R. and Nattel, S. (2006) Electrophysiological and atrial antiarrhythmic effects of a novel IKur/Kv1.5 anti-arrhythmic drug therapy for AF 663 (Abstract). Heart Rhythm, 3, S183. doi:10.1016/j.hrthm.2006.02.549

[109] Carlsson, L., Chartier, D. and Nattel, S. (2006) Characterization of the in vivo and in vitro electrophysiological effects of the novel antiarrhythmic agent AZD7009 in atrial and ventricular tissue of the dog. Journal of Car- 
diovascular Pharmacology, 47, 123-132. doi:10.1097/01.fjc.0000196242.04384.c3

[110] De Haan, S., Greiser, M., Harks, E., Blaauw, Y., van Hunnik, A., Verheule, S., et al. (2006) AVE0118, blocker of the transient outward current (I(to)) and ultrarapid delayed rectifier current (I(Kur)), fully restores atrial contractility after cardioversion of atrial fibrillation in the goat. Circulation, 114, 1234-1242. doi:10.1161/CIRCULATIONAHA.106.630905

[111] Lofberg, L., Jacobson, I. and Carlsson, L. (2006) Electrophysiological and antiarrhythmic effects of the novel antiarrhythmic agent AZD7009: A comparison with azimilide and AVE0118 in the acutely dilated right atrium of the rabbit in vitro. Europace, 8, 549-557. doi:10.1093/europace/eul061

[112] Crijns, H.J., Van Gelder, I.C., Walfridsson, H., Kulakowski, P., Ronaszeki, A., Dedek, V., et al. (2006) Safe and effective conversion of persistent atrial fibrillation to sinus rhythm by intravenous AZD7009. Heart Rhythm, 3, 1321-1331. doi:10.1016/j.hrthm.2006.06.035

[113] Okishige, K., Fukunami, M., Kumagai, K., Atarashi, H., Inoue, H. and Pilsicainide Suppression Trial for Persistent Atrial Fibrillation II Investigators (2006) Pharmacological conversion of persistent atrial fibrillation into sinus rhythm with oral pilsicainide: Pilsicainide suppression trial for persistent atrial fibrillation II. Circulation Journal, 70, 657-661. doi:10.1253/circj.70.657

[114] Antzelevitch, C., Belardinelli, L., Zygmunt, A.C., Burashnikov, A., Di Diego, J.M., Fish, J.M., et al. (2004) Electrophysiological effects of ranolazine, a novel antianginal agent with antiarrhythmic properties. Circulation, 110, 904-910. doi:10.1161/01.CIR.0000139333.83620.5D

[115] Burashnikov, A., Di Diego, J.M., Zygmunt, A.C., Belardinelli, L. and Antzelevitch, C. (2007) Atrium-selective sodium channel block as a strategy for suppression of atrial fibrillation: Differences in sodium channel inactivation between atria and ventricles and the role of ranolazine. Circulation, 116, 1449-1457. doi:10.1161/CIRCULATIONAHA.107.704890

[116] Schlotthauer, K. and Bers, D.M. (2000) Sarcoplasmic reticulum $\mathrm{Ca}(2 \mathrm{p})$ release causes myocyte depolarization. Underlying mechanism and threshold for triggered action potentials. Circulation Research, 87, 774-780. doi:10.1161/01.RES.87.9.774

[117] Chen, Y.J., Chen, S.A., Chen, Y.C., Yeh, H.I., Chang, M.S. and Lin, C.I. (2002) Electrophysiology of single cardiomyocytes isolated from rabbit pulmonary veins: Implication in initiation of focal atrial fibrillation. Basic Research in Cardiology, 97, 26-34. doi:10.1007/s395-002-8384-6

[118] Vest, J.A., Wehrens, X.H., Reiken, S.R., Lehnart, S.E., Dobrev, D., Chandra, P., et al. (2005) Defective cardiac ryanodine receptor regulation during atrial fibrillation. Circulation, 111, 2025-2032. doi:10.1161/01.CIR.0000162461.67140.4C

[119] Bers, D.M. (2004) Macromolecular complexes regulating cardiac ryanodine receptor function. Journal of Molecular and Cellular Cardiology, 37, 417-429. doi:10.1016/j.yjmcc.2004.05.026
[120] Kumagai, K., Nakashima, H., Gondo, N. and Saku, K. (2003) Antiarrhythmic effects of JVT-519, a novel cardiprotective drug, on atrial fibrillation/flutter in a canine sterile pericarditis model. Journal of Cardiovascular Electrophysiology, 14, 880-884. doi:10.1046/j.1540-8167.2003.03050.x

[121] Chen, Y.J., Chen, Y.C., Wongcharoen, W., Lin, C.I. and Chen, S.A. (2007) Effect of K201, a novel antiarrhythmic drug on calcium handling and arrhythmogenic activity of pulmonary vein cardiomyocytes. British Journal of Pharcology, 153, 915-925. doi:10.1038/sj.bjp.0707564

[122] Firouzi, M., Ramanna, H., Kok, B., Jongsma, H.J., Koeleman, B.P., Doevendans, P.A., et al. (2004) Association of human connexin40 gene polymorphisms with atrial vulnerability as a risk factor for idiopathic atrial fibrillation. Circulation Research, 95, 29-33. doi:10.1161/01.RES.0000141134.64811.0a

[123] Aonuma, S., Kohama, Y., Makino, T. and Fujisawa, T. (1982) Studies on heart XXI. Amino acid sequence of antiarrhythmic peptide (AAP) isolated from atria. Journal of Pharmacobio-Dynamics, 5, 40-48. doi:10.1248/bpb1978.5.40

[124] Weng, S., Lauven, M., Schaefer, T., Polontchouk, L., Grover, R. and Dhein, S. (2002) Pharmacological modification of gap junction coupling by an antiarrhythmic peptide via protein kinase $\mathrm{C}$ activation. The FASEB Journal, 16, 1114-1116.

[125] Haugan, K., Olsen, K.B., Hartvig, L., Petersen, J.S., HolsteinRathlou, N.H., Hennan, J.K. et al. (2005) The antiarrhythmic peptide analog ZP123 prevents atrial conduction slowing during metabolic stress. Journal of Cardiovascular Electrophysiology, 16, 537-545. doi:10.1111/j.1540-8167.2005.40687.x

[126] Guerra, J.M., Everett, T.H. 4th, Lee, K.W., Wilson, E. and Olgin, J.E. (2006) Effects of the gap junction modifier rotigaptide (ZP123) on atrial conduction and vulnerability to atrial fibrillation. Circulation, 114, 110-118. doi:10.1161/CIRCULATIONAHA.105.606251

[127] Shiroshita-Takeshita, A., Sakabe, M., Haugan, K., Hennan, J.K. and Nattel, S. (2007) Model-dependent effects of the gap junction conduction-enhancing antiarrhythmic peptide rotigaptide (ZP123) on experimental atrial fibrillation in dogs. Circulation, 115, 310-318. doi:10.1161/CIRCULATIONAHA.106.665547

[128] Rossman, E.I., Liu, K., Morgan, G.A., Swillo, R.E., Butera, J., Gruver, M., et al. (2007) Effects of the gap junction modifier, GAP-134, on conduction and atrial fibrillation/flutter inducibility in dogs (Abstract 1837). Circulation, 114.

[129] Lee, K.W., Everett, T.H., Rahmutula, D., Guerra, J.M., Wilson, E., Ding, C., et al. (2006) Pirfenidone prevents the development of a vulnerable substrate for atrial fibrillation in a canine model of heart failure. Circulation, 114, 1703-1712. doi:10.1161/CIRCULATIONAHA.106.624320

[130] Schauerte, P., Scherlag, B.J., Pitha, J., Scherlag, M.A., Reynolds, D., Lazzara, R., et al. (2000) Catheter ablation of cardiac autonomic nerves for prevention of vagal atrial fibrillation. Circulation, 102, 2774-2780. 


\section{doi:10.1161/01.CIR.102.22.2774}

[131] Smeets, J.L.R.M., Allessie, M.A., Lammers, W.J., Bonke, F.L. and Hollen, J. (1986) The wavelength of the cardiac impulse and reentrant arrhythmias in isolated rabbit atrium: The role of heart rate, autonomic transmitters, temperature, and potassium. Circulation Research, 58, 96-108. doi:10.1161/01.RES.58.1.96

[132] Allessie, M.A. (1998) Atrialelectrophysiologic remodeling: another vicious circle? Journal of Cardiovascular Electrophysiology, 9, 1378-1393. doi:10.1111/j.1540-8167.1998.tb00114.x

[133] Scanavacca, M., Cristiano, P., Hachul, D., Lara, S., Hardy, C., Darrieux, F., et al. (2006) Selective atrial vagal denervation guided by evoked vagal reflex to treat patients with paroxysmal atrial fibrillation. Circulation, 114, 876-885. doi:10.1161/CIRCULATIONAHA.106.633560

[134] Pappone, C., Santinelli, V., Manguso, F., Vicedomini, G., Gugliotta, F., Augello, G., et al. (2004) Pulmonary vein denervation enhances long-term benefit after circumferential ablation for paroxysmal atrial fibrillation. Circulation, 109, 327-334. doi:10.1161/01.CIR.0000112641.16340.C7

[135] Nakagawa, H., Scherlag, B.J., Wu, R., Po, S., Lockwood, D., Yokoyama, K., et al. (2004) Addition of selective ablation of autonomic ganglia to pulmonary vein antrum isolation for treatment of paroxysmal and persistent atrial fibrillation. Circulation, 110, III-459.

[136] Fox, C.S., Parise, H., D’Agostino, R.B.Sr., Lloyd-Jones, D.M., Vasan, R.S., Wang, T.J., et al. (2004) Parental atrial fibrillation as a risk factor for atrial fibrillation in offspring. JAMA, 291, 2851-2855. doi:10.1001/jama.291.23.2851

[137] Arnar, D.O., Thorvaldsson, S., Manolio, T.A., Thorgeirsson, G., Kristjansson, K., Hakonarson, H., et al. (2006) Familial aggregation of atrial fibrillation in Iceland. European Heart Journal, 27, 708-712. doi:10.1093/eurheartj/ehi727
[138] Darbar, D., Herron, K.J., Ballew, J.D., Jahangir, A., Gersh, B.J., Shen, W.K., et al. (2003) Familial atrial fibrillation is a genetically heterogeneous disorder. Journal of the American College of Cardiology, 41, 2185-2192. doi:10.1016/S0735-1097(03)00465-0

[139] Ellinor, P.T., Yoerger, D.M., Ruskin, J.N. and MacRae, C.A. (2005) Familial aggregation in lone atrial fibrillation. Human Genetics, 118, 179-184. doi:10.1007/s00439-005-0034-8

[140] Christophersen, I.E., Ravn, L.S., Budtz-Joergensen, E., Skytthe, A., Haunsoe, S., Svendsen, J.H., et al. (2009) Familial aggregation of atrial fibrillation: A study in danish twins. Circulation: Arrhythmia and Electrophysiology, 2, 378-383.

[141] Chen, Y.H., Xu, S.J., Bendahhou, S., Wang, X.L., Wang, Y., Xu, W.Y., Jin, H.W., et al. (2003) Kcnq1 gain-offunction mutation in familial atrial fibrillation. Science, 299, 251-254. doi:10.1126/science.1077771

[142] Yang, Y., Xia, M., Jin, Q., Bendahhou, S., Shi, J., Chen, Y., et al. (2004) Identification of a kcne2 gain-of-function mutation in patients with familial atrial fibrillation. The American Journal of Human Genetics, 75, 899-905. doi:10.1086/425342

[143] Gollob, M.H., Jones, D.L., Krahn, A.D., Danis, L., Gong, X.Q., Shao, Q., Liu, X., et al. (2006) Somatic mutations in the connexin 40 gene (gja5) in atrial fibrillation. The New England Journal of Medicine, 354, 2677-2688. doi:10.1056/NEJMoa052800

[144] Hodgson-Zingman, D.M., Karst, M.L., Zingman, L.V., et al. (2008) Atrial natriuretic peptide frameshift mutation in familial atrial fibrillation. The New England Journal of Medicine, 359, 158-165. doi:10.1056/NEJMoa0706300

[145] Benjamin, E.J., Chen, P.S., Bild, D.E., Mascette, A.M., Albert, C.M., Alonso, A., et al. (2009) Prevention of atrial fibrillation: Report from a national heart, lung, and blood institute workshop. Circulation, 119, 606-618. doi:10.1161/CIRCULATIONAHA.108.825380 